\title{
Use of Lexical Stress during Oral Reading among Japanese EFL Learners
}

\author{
Lisa Yoshikawa, Chi Yui Leung \\ Graduate School of International Development, Nagoya University, Nagoya, Japan \\ Email: lisay@nagoya-u.jp
}

Received 15 September 2014; revised 8 October 2014; accepted 1 November 2014

Copyright (C) 2014 by authors and Scientific Research Publishing Inc.

This work is licensed under the Creative Commons Attribution International License (CC BY). http://creativecommons.org/licenses/by/4.0/

(c) (i) Open Access

\section{Abstract}

The purpose of the present study is to examine second language (L2) oral reading with a focus on lexical stress. We conducted oral reading tasks to investigate whether 14 Japanese learners of English as a foreign language (EFL) read words aloud with different lexical stress (one- or twostress words) with appropriate stress assignment, similar to a comparison group of 14 native English speakers, in order to see whether EFL learners, who have fewer verbal input and output opportunities, assign the proper stress(es) in oral reading contexts. The participants read 18 pairs of four-syllable one- and two-stress words both in isolation and in sentence context conditions, and the whole word duration, syllable duration, and syllable intensity were analyzed. The results showed that both groups of readers (1) read two-stress words longer than one-stress words and (2) read stressed syllables longer than unstressed syllables with appropriate stress assignment. Our findings suggest that intermediate EFL learners can recognize and manipulate $L 2$ prosodic information, even though their L1 does not possess the property. Future directions for L2 oral reading research development are discussed.

\section{Keywords}

Prosody, Oral Reading, Lexical Stress, Second Language Reading, English as a Foreign Language

\section{Introduction}

According to Wagner and Watson (2010), prosody comprises sphonological properties in speech, such as rise or fall of pitch and intonation, stress, and rhythm, which are all reflected by acoustic characteristics, from which semantic and syntactic cues are provided for language comprehension. Prosody is involved in any language use situation. It functions to express the attitude or intension of speakers, and listeners try to understand their interlocutors' utterances mediated by prosodic features (Wagner \& Watson, 2010). 
Prosody also facilitates language processing in written input processing, i.e., reading and writing (e.g., Fodor, 1998; Kuhn, Schwanenflugel, \& Meisinger, 2010), because readers extract sound information from orthographies, as text represents spoken language, although differences in transparency exist between graphemes and phonemes (Perfetti, 2003; Perfetti, Cao, \& Booth, 2013). Previous studies report that readers make pauses at the end of clauses or every meaningful unit (Hirotani, Frazier, \& Rayner, 2006) for the sake of appropriate sentence comprehension and reading fluency. Schreiber (1991) underlines that a deficit in text segmentation (chunking) skills would lead to lack of reading fluency, even though readers' decoding skills are efficient. The recognition is prevalent that prosody is involved in reading among first language (L1) readers. It is not, however, necessarily the case for second language (L2) readers, especially for those who learn English as a foreign language (EFL). The present study focused on this area to accumulate a database for future exploitation.

L1 Studies by Miller and Schwanenflugel, for example, contribute, through underpinning the examination and assessment of prosody skills in reading development, toward an understanding of their role in reading. In 2006, they reported that children's sentence reading accuracy and speed are associated with appropriate pausing and pitch changes (Miller \& Schwanenflugel, 2006). Furthermore, Miller and Schwanenflugel (2008) examined the effect of reading prosody development on later reading skills among young children (from first to second grade) and revealed that the decrease of inappropriate and/or lengthy pauses significantly accounted for the variance in reading comprehension when the students were in their third grade. Their findings demonstrate that prosodic processing skills are a base for reading developments, thus supporting Schreiber's (1991) view.

In the field of L2 oral reading research, however, the majority of studies have rather purposefully dropped prosody measures (e.g., pause lengths, intonation contours, pitch change) as predictive variables to estimate reading comprehension skills, because researchers have not reached a consistent agreement on prosody measures and the assessments that reflect well the EFL learning environment, where oral input is considerably limited and literacy learning occurs with less reliance on oral information and processing (Fuchs, Fuchs, Hosp, \& Jenkins, 2001; Jeon, 2012; Jiang, Sawaki, \& Sabatini, 2012). However, they believe it is involved in L2 reading as an independent variable. Nonetheless, Jiang et al. (2012) could not obtain a significant contribution of prosody measures to reading comprehension skills above and beyond the effects of other oral reading measures (reading rate and accuracy). Yamashita and Amano (2011) examined whether and how reading prosody (pause length and pitch changes) relates to word recognition and reading comprehension skills among college level Japanese EFL learners. They found that pause length only correlated with word recognition. Furthermore, Goss and Nakayama (2011) revealed that sentence prosody produced by L1-English learners of Japanese as a foreign language did not reflect their sentence comprehension accuracy, indicating an inconsistent relation between prosody production and comprehension. A detailed description by Stephens (2011) of the actual circumstance of prosody instruction in Japanese EFL classrooms shows that Japanese students receive little, if any, instruction on prosody features, because the higher priority is instead placed on vocabulary and grammar instruction. The overlook of prosody instruction in classrooms may also prevent an understanding of the extent to which EFL learners make use of prosody in oral reading and how its use affects reading performance.

One of the implications in the literature is that it is effortful to seek correlational and predictive variables among various prosodic features in sentence-level reading contexts, due to the unestablished assessment methods and internal and external factors surrounding each learner, such as the learner's degree of reliance on prosodic cues in reading, proficiency, and learning readiness (Fuchs et al., 2001; Yamashita \& Amano, 2011), thus resulting in the inconsistent findings between L1 and L2 research. Investigating prosodic measures at the sentence-level and providing practical suggestions for a measurement scale are beyond our purposes, but we focused on word-level prosody, i.e., lexical stress, to see whether EFL participants (L1-Japanese speakers) with few oral input and output opportunities make use ofL2 prosodic features properly in oral reading contexts. Lexical stress is a stable prosodic feature that is assigned for each word to distinguish word meanings and is processed during the phase of lexical access (Gutiérrez-Palma \& Palma-Reyes, 2008). Therefore, if the participants in this study produce the correct prosody, the results will indicate that theiroral performances purely reflect their knowledge of stress assignment for each word (Kuriyagawa \& Sawashima, 1989) and that the lexical stress information is retrieved during the phase of lexical access or word recognition (e.g., Gutiérrez-Palma \& PalmaReyes, 2008). Another point to focus in this study is the difference of prosodic features in learners' L1 and L2. L1-Japanese speakers rely on pitch accent, using syllable-timed rhythm, to distinguish competitive words that share the same phones, whereas L1-English speakers rely on lexical stress, using stress-timed rhythm. The commonality of prosody use at the word level may not necessarily mean that either L1 group is able to manipulate 
the other prosody feature during oral reading, especially those within the EFL environment. Thus, we examined whether the EFL learners in this study are able to recognize and manipulate word-level L2 prosodic information (lexical stress) during oral reading and perform properly, i.e., similar toL1-English speakers, in order to answer the addressed questions. Based on the previous literature (Hirata, 2004; Hoequist, 1985), we assessed whole word duration, syllable duration, and syllable intensity as measurements of lexical stress. This study is a step toward a better understanding of the interplay of prosody and the reading process.

\section{Methods}

\subsection{Participants}

Fourteen Japanese EFL university students (11 male and three female with an age range of 19 - 28) and native English-speaking students (10 male and four female with an age range of 18 - 27) at Nagoya University were paid to participate in the present study, without knowing the purpose of the study. They were part of a larger study examining the relationship between their silent reading process and prosodic processing. All the Japanese participants were native Japanese speakers who had received a formal English education of at least six years in Japan. Their English proficiency was intermediate, as indicated by their TOEFL ITP scores $(M=522$; $S D=$ 30.38). Only one of the 14 Japanese participants had had more than 1 year of experience studying abroad in the United States. Asher experience abroad did not skew the results (her performance data were within the standard deviation), the analysis was performed using the oral data of all 14 participants.

\subsection{Materials}

Eighteen pairs of four syllable words (nouns and adjectives) were extracted from the JACET List of 8000 Basic Words (JACET Committee of Basic Words Revision, 2003) and MRC psycholinguistic database (Coltheart, 1981). The word length, word frequency (British National Corpus), and part of speech were matched between pairs. The number of stressed syllable(s) of the paired words was manipulated: one-stress words and two-stress words, based on the Merriam-Webster's online dictionary, which is available at http://www.m-w.com/dictionary. Stress was on the second syllable for the one-stress words and on the first and third syllables for the two-stress words. In the item selection process, we also controlled for word familiarity between pairs, by conducting a familiarity judgment task with 24 Japanese university students to ensure that all the stimuli were known to the participants.

For the sentence-reading task (explained below), 18 sets of sentences were created, which contained one of the paired words in each sentence (see the example sentences in Table 1). The contextual predictability (using cloze tests) and plausibility of the sentences that were estimated by 19 native English speakers were matched between the conditions.

\subsection{Procedure}

Before the experiments, written consent was obtained from each of the participants. All oral data were collected individually and recorded with a voice recorder in a sound-proof room. Two tasks were given in order to avoid task effects: isolation reading and sentence reading. In both reading tasks, the participants were asked to look at a computer screen that presented the target words as either isolated or embedded in a sentence, and to read the text aloud as accurately as possible under untimed conditions. Isolation reading was preceded by the sentence reading task. The participants were given a short break halfway through each session to reduce fatigue.

Table 1. Example sentences.

\begin{tabular}{ll}
\hline \multicolumn{1}{c}{ One-stress words } & Two-stress words \\
\hline He is a well-known traditional artist in Japan. & He is a well-known independent artist in Japan. \\
His bad behavior should be stopped. & His bad politics should be stopped. \\
His powerful argument caused some problems. & His powerful attitude caused some problems. \\
The famous reporter works really hard. & The famous employee works really hard.
\end{tabular}




\subsection{Analysis}

Any mispronunciation or stumbling responses were excluded from the sound analysis (5 and 26 responses for the Japanese participants, hereafter, NNS; and 2 and 7 responses for the native English participants, hereafter NS; in the isolated and context readings, respectively), although nonnative pronunciations for NNS data were allowed. This procedure reduced the number of items for analysis to 499 and 478 words for NNS and 502 and 497 words for NS in the isolated and context readings, respectively. The three acoustic measures (word duration, syllable duration and syllable intensity) were calculated using Praat ver. 5.3.50. We regard the stressed syllables as having longer durations and higher intensities (Hirata, 2004; Hoequist, 1985; Kuriyagawa \& Sawashima, 1989). The target words were either one- or two-stress words, with the second syllable stressed in the former and the first and third in the latter. Our expectations are thus that the mean syllable duration and the mean syllable intensity for one-stress words were longest and highest on the second syllable, whereas for two-stress words they would be on the first and third.

\section{Results}

Firstly, a paired-samples $t$-test was conducted to compare the mean word durations (ms) in one- and two-stress words for both the NNS and NS data in both reading conditions. As for isolation reading, there was a significant difference in the reading times for one-stress $(M=768, S D=74,95 \%$ CI [763, 773]) and two-stress words ( $M=$ 804, $S D=68,95 \%$ CI [799, 809]), $t(13)=-3.57, p<.01, d=0.51$, showing that two-stress words were read longer than one-stress words, and NS data also showed that one-stress $(M=673, S D=74,95 \%$ CI [667, 679]) were read shorter than two-stress words $(M=705, S D=90,95 \%$ CI $[698,712]), t(13)=-5.86, p<.001, d=$ 0.38 .

In sentence reading, NNS read one-stress $(M=692, S D=60,95 \%$ CI $[688,696])$ shorter than the two-stress words $(M=732, S D=61,95 \%$ CI $[728,736]), t(13)=-4.89, p<.001, d=0.66$. Similarly, NS data showed the shorter word duration for one-stress $(M=582, S D=48,95 \% \mathrm{CI}[578,586])$ than the two-stress words $(M=621$, $S D=60,95 \%$ CI $[616,626]), t(13)=-6.70, p<.001, d=0.71$. In addition, one-stress words for isolation reading were read longer than in sentence reading, $t(13)=3.71, p<.01, d=1.12$ for NNS and $t(13)=8.18, p<.001$, $d=1.45$ for NS, and two-stress shorter for isolation than for sentence, $t(13)=3.71, p<.01, d=1.11$ for NNS and $t(13)=7.28, p<.001, d=1.10$ for NS).

\subsection{Mean Syllable Duration (ms) in Isolation Reading}

Table 2 summarizes the mean syllable durations (ms) and the intensities (dB) and the SDs for the both groups in both reading conditions. A two-way analysis of variance (ANOVA) was conducted with Stress (one-stress words vs. two-stress words) and Position (the first vs. second vs. third vs. fourth syllables) for each group in each reading condition to see whether they read one- and two-stress words differently.

First, the syllable duration measures for NNS in isolation reading showed a significant effect (only in the participant analysis, hereafter PA) for Stress, $F 1(1,13)=24.54, p<.001, \eta_{\mathrm{p}}{ }^{2}=.66, F 2(1,17)=3.06, p=.098, \eta_{\mathrm{p}}{ }^{2}$ $=.16$; for Position, $F 1(1.42,18.42)=169.88, p<.001, \eta_{\mathrm{p}}{ }^{2}=.93, F 2(3,51)=19.59, p<.001, \eta_{\mathrm{p}}{ }^{2}=.54$; and the Stress and Position interaction, $F 1(2.68,34.80)=53.90, p<.001, \eta_{\mathrm{p}}{ }^{2}=.81, F 2(3,51)=3.12, p<.05, \eta_{\mathrm{p}}{ }^{2}=.16$.

The same pattern of results was obtained in NS data; a significant effect (only in PA) for Stress, $F 1(1,13)=$ 29.31, $p<.001, \eta_{\mathrm{p}}{ }^{2}=.70, \mathrm{~F} 2(1,17)=1.90, n s, \eta_{\mathrm{p}}{ }^{2}=.11$; for Position, $F 1(1.34,17.39)=84.51, p<.001, \eta_{\mathrm{p}}{ }^{2}$ $=.87, F 2(1.75,29.70)=11.24, p<.001, \eta_{p}{ }^{2}=.40$; and the Stress and Position interaction, $F 1(2.32,30.21)=$ 159.07, $p<.001, \eta_{\mathrm{p}}{ }^{2}=.93, \mathrm{~F} 2(2.96,50.24)=6.44, p<.01, \eta_{\mathrm{p}}{ }^{2}=.28$.

Post hoc analyses using the Bonferroni criterion for the simple main effect of Stress by Position for NNS data revealed that the mean syllable durations for the first syllables between the word conditions were not significantly different, $F 1(1,13)=0.24, n s, d=0.13, \eta_{\mathrm{p}}{ }^{2}=.02, F 2(1,17)=0.03, n s, d=0.07, \eta_{\mathrm{p}}{ }^{2}=.01$; the second syllable for one-stress was read significantly longer than for two-stress words (only in PA), $F 1(1,13)=110.31$, $p<.001, d=1.85, \eta_{\mathrm{p}}{ }^{2}=.90, F 2(1,17)=3.83, p=.07, d=0.71, \eta_{\mathrm{p}}{ }^{2}=.19$; the third syllable for one-stress was read significantly shorter than for two-stress words, $F 1(1,13)=97.98, p<.001, d=2.60, \eta_{\mathrm{p}}{ }^{2}=.89, F 2(1,17)=$ 5.49, $p<.05, d=0.72, \eta_{\mathrm{p}}{ }^{2}=.25$; and the fourth syllables between the word conditions were not significantly different (only in item analysis, hereafter IA), $F 1(1,13)=38.35, p<.001, d=1.28, \eta_{\mathrm{p}}{ }^{2}=.75, F 2(1,17)=2.45$, $n s, d=0.40, \eta_{\mathrm{p}}^{2}=.13$. 
Table 2. Means and standard deviations (within parentheses) for the syllable durations (ms) and peak intensities (dB) in isolation and sentence context reading.

\begin{tabular}{|c|c|c|c|c|}
\hline \multirow[b]{2}{*}{ Stress pattern } & \multicolumn{4}{|c|}{ Syllable position } \\
\hline & Syllable 1 & Syllable 2 & Syllable 3 & Syllable 4 \\
\hline One-stress words & Weak & Strong & Weak & Weak \\
\hline \multirow[t]{2}{*}{ Two-stress words } & Strong & Weak & Strong & Weak \\
\hline & & lation reading & & \\
\hline \multicolumn{5}{|l|}{ One-stress words (NNS) } \\
\hline Syllable duration & $163(23)$ & $191(23)$ & 159 (15) & $256(32)$ \\
\hline Peak intensity & $64.08(4.85)$ & $69.16(5.15)$ & $64.96(5.10)$ & $61.08(4.14)$ \\
\hline \multicolumn{5}{|l|}{ One-stress words (NS) } \\
\hline Syllable duration & $142(21)$ & $184(19)$ & 139 (14) & $209(32)$ \\
\hline Peak intensity & $64.62(2.00)$ & $69.80(3.94)$ & $65.03(3.09)$ & $61.78(2.26)$ \\
\hline \multicolumn{5}{|l|}{ Two-stress words (NNS) } \\
\hline Syllable duration & $166(25)$ & $154(17)$ & 209 (23) & 290 (19) \\
\hline Peak intensity & $65.65(5.40)$ & $65.98(4.87)$ & $67.41(4.95)$ & $60.66(3.94)$ \\
\hline \multicolumn{5}{|l|}{ Two-stress words (NS) } \\
\hline Syllable duration & $149(26)$ & $128(15)$ & $185(22)$ & $243(40)$ \\
\hline \multirow[t]{2}{*}{ Peak intensity } & $68.56(3.08)$ & $65.85(2.87)$ & $67.36(3.97)$ & $61.31(2.46)$ \\
\hline & & tence reading & & \\
\hline \multicolumn{5}{|l|}{ One-stress words (NNS) } \\
\hline Syllable duration & 150 (17) & $193(27)$ & $146(24)$ & 219 (27) \\
\hline Peak intensity & $67.52(4.70)$ & $70.96(5.21)$ & $67.35(5.03)$ & $68.43(5.21)$ \\
\hline \multicolumn{5}{|l|}{ One-stress words (NS) } \\
\hline Syllable duration & 137 (18) & $178(18)$ & $120(14)$ & $166(20)$ \\
\hline Peak intensity & $67.80(3.00)$ & $72.51(3.83)$ & $67.78(2.94)$ & $68.63(3.57)$ \\
\hline \multicolumn{5}{|l|}{ Two-stress words (NNS) } \\
\hline Syllable duration & $170(26)$ & $134(23)$ & $205(22)$ & $240(22)$ \\
\hline Peak intensity & $69.40(5.40)$ & $67.34(4.72)$ & $70.27(5.18)$ & $67.41(5.11)$ \\
\hline \multicolumn{5}{|l|}{ Two-stress words (NS) } \\
\hline Syllable duration & $162(15)$ & 109 (13) & 180 (19) & $182(26)$ \\
\hline Peak intensity & $71.58(3.05)$ & $68.00(3.63)$ & $71.00(3.84)$ & $67.34(3.21)$ \\
\hline
\end{tabular}

In contrast, the simple main effect of Position by Stress for one-stress words for NNS data revealed the following results: the first syllable was read shorter than the second (only in PA) and fourth without significant difference with the third syllables; the second syllable was read longer than the third but shorter than the fourth only in PA, which was the longest duration, $F 1(3,39)=84.13, p<.001, \eta_{\mathrm{p}}{ }^{2}=.87, F 2(3,51)=6.33, p<.01, \eta_{\mathrm{p}}{ }^{2}$ $=.28$. In two-stress words, the first syllable was read longer than the second (only in PA) and shorter than the third (only in PA) and fourth syllables, and the second syllable was read shorter than the third (only in PA) and fourth, which was the longest, $F 1(3,39)=194.06, p<.001, \eta_{\mathrm{p}}{ }^{2}=.94, F 2(3,51)=20.54, p<.001, \eta_{\mathrm{p}}{ }^{2}=.55$. 
Post-hoc Bonferroni tests for the simple main effects of Stress by Position for NS data showed that the first syllables between the word conditions were not significantly different, $F 1(1,13)=3.34, p=.09, d=0.30, \eta_{\mathrm{p}}{ }^{2}$ $=.21, F 2(1,17)=0.17, n s, d=0.07, \eta_{\mathrm{p}}{ }^{2}=.02$; the second syllable for one-stress was read longer than for two-stress words, $F 1(1,13)=366.03, p<.001, d=3.31, \eta_{\mathrm{p}}{ }^{2}=.97, F 2(1,17)=10.97, p<.01, d=1.18, \eta_{\mathrm{p}}{ }^{2}$ $=.40$; the third syllable for one-stress was read shorter than for two-stress words, $F 1(1,13)=189.09, p<.001, d$ $=2.53, \eta_{\mathrm{p}}^{2}=.94, F 2(1,17)=9.91, p<.01, d=0.86, \eta_{\mathrm{p}}^{2}=.37$; and the fourth syllables between the word conditions were not significantly different (only in IA), F1(1,13) $=91.43, p<.001, d=0.93, \eta_{\mathrm{p}}{ }^{2}=.88, F 2(1,17)=$ 3.59, $p=.08, d=0.44, \eta_{\mathrm{p}}^{2}=.18$.

In contrast, the simple main effect of Position by Stress with post-hoc Bonferroni tests for one-stress words for NS data revealed that the mean duration of the first syllable was read shorter than the second and fourth syllables only in PA, and the second syllable longer than the third but shorter than the fourth, which was the longest duration, $F 1(3,39)=75.49, p<.001, \eta_{\mathrm{p}}{ }^{2}=.86, F 2(3,51)=4.91, p<.01, \eta_{\mathrm{p}}{ }^{2}=.23$. In two-stress words, the first syllable was read longer than the second (only in PA) and shorter than the third (only in PA) and fourth syllables, and the second shorter than the third and fourth, which was the longest duration, $F 1(3,39)=111.99, p<.001$, $\eta_{\mathrm{p}}{ }^{2}=.90, F 2(3,51)=15.43, p<.001, \eta_{\mathrm{p}}{ }^{2}=.48$. Figure 1 illustrates the Bonferroni $t$-tests of the simple main effect of Position for the mean syllable duration in isolation reading for precision. The significant differences between the fourth and the other syllables were not shown, in the interest of simplicity.

\subsection{Mean Syllable Intensity (dB) in Isolation Reading}

For syllable intensity $(\mathrm{dB})$ measures in isolation reading, NNS data showed a non-significant effect for Stress, $F 1(1,13)=0.45, n s, \eta_{\mathrm{p}}{ }^{2}=.04, F 2(1,17)=0.28, n s, \eta_{\mathrm{p}}{ }^{2}=.02$; a significant effect for Position, $F 1(1.85,24.04)=$ $60.83, p<.001, \eta_{\mathrm{p}}{ }^{2}=.83, F 2(1.87,31.84)=48.88, p<.001, \eta_{\mathrm{p}}{ }^{2}=.75$; and the Stress and Position interaction, $F 1(2.23,28.93)=35.86, p<.001, \eta_{\mathrm{p}}{ }^{2}=.74, F 2(2.56,43.47)=14.35, p<.001, \eta_{\mathrm{p}}{ }^{2}=.46$, while NS data showed a significant effect for Stress (only in PA), $F 1(1,13)=7.16, p<.05, \eta_{\mathrm{p}}{ }^{2}=.36, F 2(1,17)=1.97, n s, \eta_{\mathrm{p}}{ }^{2}=.11$; for Position, $F 1(1.94,25.20)=52.64, p<.001, \eta_{\mathrm{p}}{ }^{2}=.81, F 2(1.87,31.75)=72.58, p<.001, \eta_{\mathrm{p}}{ }^{2}=.82$; and the Stress and Position interaction, $F 1(1.40,18.26)=89.53, p<.001, \eta_{\mathrm{p}}{ }^{2}=.88, F 2(2.27,38.66)=31.62, p<.001$, $\eta_{\mathrm{p}}^{2}=.66$.

The results of post-hoc Bonferroni tests for the simple main effect of Stress by Position of the mean syllable intensity measures for NNS data showed that the first syllable for one-stress had lower intensity than for two-stress words, $F 1(1,13)=15.69, p<.01, d=0.31, \eta_{\mathrm{p}}{ }^{2}=.55, F 2(1,17)=4.70, p<.05, d=0.65, \eta_{\mathrm{p}}{ }^{2}=.22$; the second syllable for one-stress had higher intensity than for two-stress words, $F 1(1,13)=57.05, p<.001, d=$ $0.64, \eta_{\mathrm{p}}{ }^{2}=.82, \mathrm{~F} 2(1,17)=32.20, p<.001, d=1.67, \eta_{\mathrm{p}}^{2}=.66$; the third syllable for one-stress had lower intensity than for two-stress words, $F 1(1,13)=30.47, p<.001, d=0.49, \eta_{\mathrm{p}}{ }^{2}=.71, F 2(1,17)=15.99, p<.01, d=$ $1.11, \eta_{\mathrm{p}}{ }^{2}=.49$; and the fourth syllable did not show the significant differences between one- and two-stress

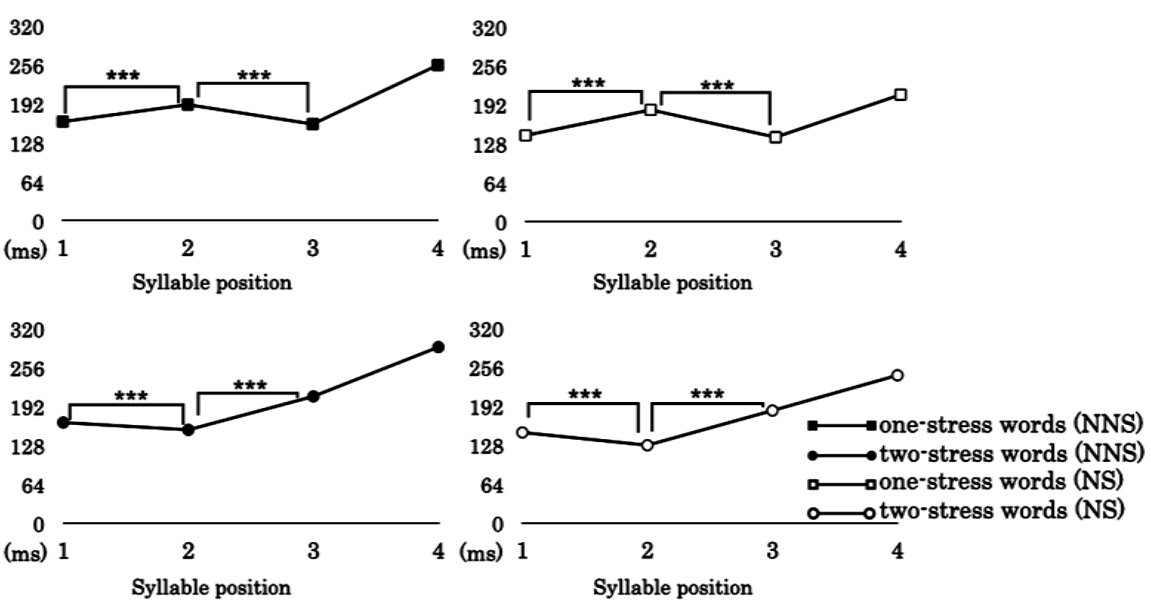

Figure 1. Results of the simple main effect of Position by Stress for the mean syllable duration in isolation reading for one-stress for NNS (the top left) and for NS (the top right) and two-stress words for NNS (the bottom left) and for NS (the bottom right). Note: ${ }^{* * *} p<.001$. 
words, $F 1(1,13)=2.12, n s, d=0.11, \eta_{\mathrm{p}}^{2}=.15, F 2(1,17)=0.56, n s, d=0.26, \eta_{\mathrm{p}}{ }^{2}=.04$.

Meanwhile, the simple main effects of Position by Stress interactions for one-stress words for NNS revealed that: the mean intensity of the first syllable was not significantly different with the third, but higher than the fourth and lower than the second syllables; the second syllable was highest intensity and the fourth lowest, $F 1(3$, $39)=53.28, p<.001, \eta_{\mathrm{p}}{ }^{2}=.81, F 2(3,51)=55.80, p<.001, \eta_{\mathrm{p}}{ }^{2}=.77$. In two-stress words, the mean intensity of the first was not significantly different from the second syllable, but lower than the third (only in PA) and higher than the fourth syllables; the second had lower intensity than the third (only in PA) and higher than the fourth, which was lowest intensity, $F 1(3,39)=56.91, p<.001, \eta_{\mathrm{p}}{ }^{2}=.82, F 2(3,51)=24.03, p<.001, \eta_{\mathrm{p}}{ }^{2}=.59$.

In contrast, NS data for the syllable intensity measures in isolation reading showed that the first syllable for one-stress had lower intensity than for two-stress words, $F 1(1,13)=67.38, p<.001, d=1.52, \eta_{\mathrm{p}}{ }^{2}=.84, F 2(1$, $17)=23.31, p<.001, d=1.59, \eta_{\mathrm{p}}{ }^{2}=.58$; the second syllable for one-stress had higher intensity than for two-stress words, $F 1(1,13)=136.58, p<.001, d=1.15, \eta_{\mathrm{p}}{ }^{2}=.92, F 2(1,17)=31.91, p<.001, d=2.12, \eta_{\mathrm{p}}{ }^{2}$ $=.66$; the third syllable for one-stress had lower intensity than for two-stress words, $F 1(1,13)=37.48, p<.001$, $d=0.66, \eta_{\mathrm{p}}{ }^{2}=.75, F 2(1,17)=17.10, p<.01, d=1.45, \eta_{\mathrm{p}}{ }^{2}=.51$; and the fourth syllables between one- and two-stress words were not significantly different (only in IA), $F 1(1,13)=6.86, p<.05, d=0.20, \eta_{\mathrm{p}}{ }^{2}=.35, F 2(1$, $17)=1.13, n s, d=0.33, \eta_{\mathrm{p}}{ }^{2}=.07$. Figure 2 summarizes the results of the simple main effect of Stress for the mean syllable durations and intensity for NNS and NS data in isolation reading.

As for the simple main effect of Position for one-stress words for NS data, we found the lower intensity of the first syllable than the second and higher than the fourth syllables, and the second had highest intensity and the fourth lowest, $F 1(3,39)=52.18, p<.001, \eta_{\mathrm{p}}{ }^{2}=.81, F 2(3,51)=58.18, p<.001, \eta_{\mathrm{p}}{ }^{2}=.78$. In two-stress words, the first had higher intensity than the second and fourth syllables, and the second had lower intensity than the third (only in PA) and higher than the fourth syllable, which had the lowest intensity, $F 1(3,39)=70.62, p$ $<.001, \eta_{\mathrm{p}}{ }^{2}=.85, \mathrm{~F} 2(3,51)=48.39, p<.001, \eta_{\mathrm{p}}^{2}=.75$.

Figure 3 illustrates the Bonferroni $t$-tests of the simple main effect of Position for the mean syllable intensity in isolation reading for precision. The significant differences between the fourth and the other syllables were not shown, in the interest of simplicity.

\subsection{Mean Syllable Duration (ms) in Sentence Reading}

First, the syllable duration measures (ms) for NNS data in sentence reading showed a significant effect for Stress (only in PA), $F 1(1,13)=17.38, p<.01, \eta_{\mathrm{p}}{ }^{2}=.58, F 2(1,17)=3.70, p=.071, \eta_{\mathrm{p}}{ }^{2}=.18$, for Position, $F 1(3,39)$ $=53.66, p<.001, \eta_{\mathrm{p}}{ }^{2}=.81, F 2(3,51)=11.72, p<.001, \eta_{\mathrm{p}}{ }^{2}=.41$, and the Stress and Position interaction, $F 1(3$, 39) $=80.24, p<.001, \eta_{\mathrm{p}}{ }^{2}=.87, \mathrm{~F} 2(3,51)=7.20, p<.001, \eta_{\mathrm{p}}{ }^{2}=.30$, whereas NS data showed a significant

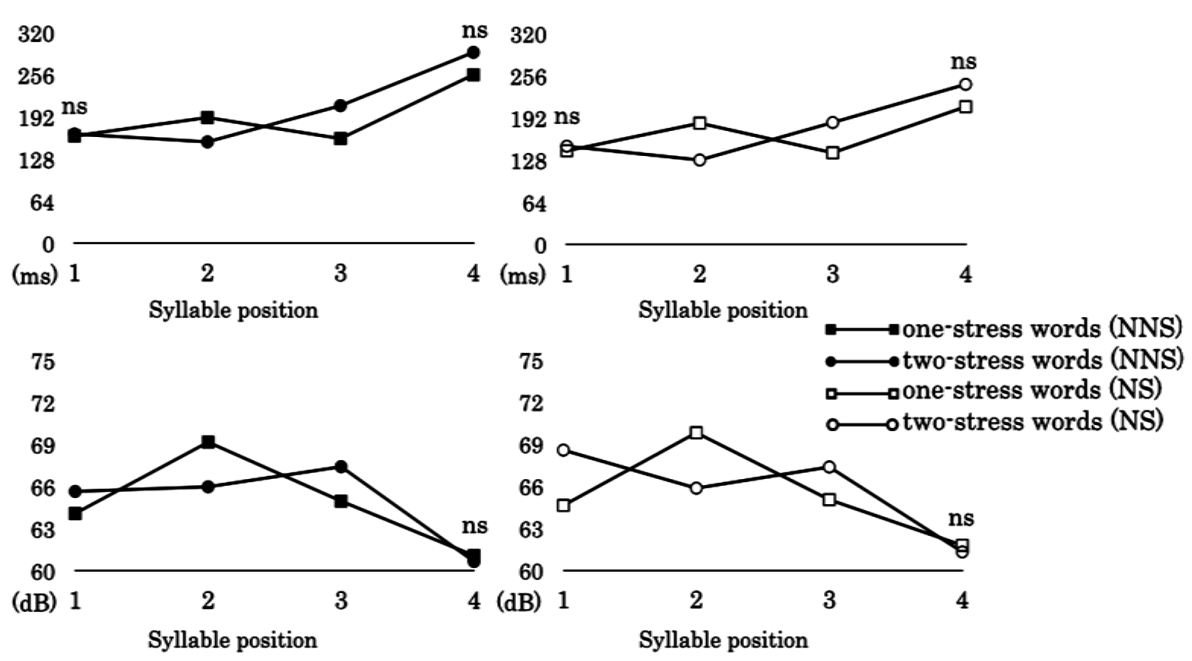

Figure 2. Results of the simple main effect of Stress for the mean syllable duration (top) for NNS (the top left) and NS (the top right) and for the mean syllable intensity (bottom) for NNS (the bottom left) and NS (the bottom right) in isolation reading. Note: All conditions without asterisks reached statistically significant levels. 

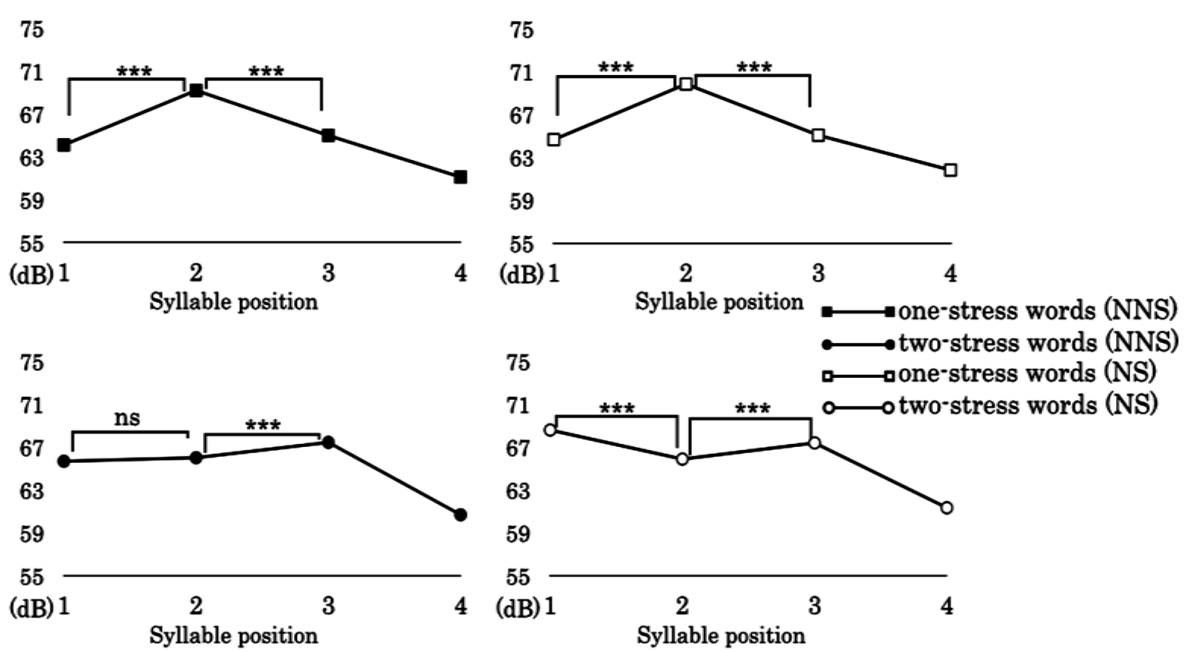

Figure 3. Results of the simple main effect of Position by Stress for the mean syllable intensity in isolation reading for one-stress for NNS (the top left) and for NS (the top right) and twostress words for NNS (the bottom left) and for NS (the bottom right). Note: ${ }^{* * *} p<.001$.

effect for Stress, $F 1(1,13)=13.17, p<.01, \eta_{\mathrm{p}}{ }^{2}=.51, F 2(1,17)=4.77, p<.05, \eta_{\mathrm{p}}{ }^{2}=.22$, for Position, $F 1(3,39)$ $=23.40, p<.001, \eta_{\mathrm{p}}{ }^{2}=.65, F 2(3,51)=3.13, p<.05, \eta_{\mathrm{p}}{ }^{2}=.16$, and the Stress and Position interaction, $F 1(3,39)$ $=102.02, p<.001, \eta_{\mathrm{p}}{ }^{2}=.89, \mathrm{~F} 2(3,51)=12.20, p<.001, \eta_{\mathrm{p}}{ }^{2}=.42$.

The result of post-hoc Bonferroni tests of the simple effect of Stress by Position for NNS data revealed that the first syllable for one-stress was read shorter than for two-stress words (only in PA), $F 1(1,13)=11.09, p$ $<.01, d=0.91, \eta_{\mathrm{p}}{ }^{2}=.47, F 2(1,17)=1.60, n s, d=0.44, \eta_{\mathrm{p}}{ }^{2}=.09$; the second syllable for one-stress was read longer than for two-stress words, $F 1(1,13)=120.53, p<.001, d=2.35, \eta_{\mathrm{p}}{ }^{2}=.91, F 2(1,17)=13.60, p<.01, d$ $=1.23, \eta_{\mathrm{p}}{ }^{2}=.45$; the third syllable for one-stress was read shorter than for two-stress words, $F 1(1,13)=114.81$, $p<.001, d=2.56, \eta_{\mathrm{p}}{ }^{2}=.90, F 2(1,17)=8.85, p<.01, d=0.94, \eta_{\mathrm{p}}{ }^{2}=.35$; and the fourth syllables between the word conditions were not significantly different (only in IA), $F 1(1,13)=21.94, p<.001, d=0.85, \eta_{\mathrm{p}}{ }^{2}=.63$, $F 2(1,17)=1.80, n s, d=0.35, \eta_{\mathrm{p}}^{2}=.10$.

In contrast, the simple main effect of Position by Stress with post-hoc Bonferroni tests for one-stress words for NNS data revealed that the mean duration of the first syllable was read shorter than the second (only in PA) and fourth syllables, and the second (only in PA) and fourth were read longer than the third syllables, $F 1(3,39)$ $=40.91, p<.001, \eta_{\mathrm{p}}{ }^{2}=.76, F 2(3,51)=6.19, p<.01, \eta_{\mathrm{p}}{ }^{2}=.27$. In two-stress words, the first syllable had longer duration than the second (only in PA) and shorter than the third (only in PA) and fourth syllables, and the second syllable was read shorter than the third and fourth, which had the longest duration (only in PA), $F 1(3,39)=$ 87.28, $p<.001, \eta_{\mathrm{p}}{ }^{2}=.88, F 2(3,51)=13.84, p<.001, \eta_{\mathrm{p}}{ }^{2}=.45$.

Next, post-hoc Bonferroni tests for the simple main effect of Stress for NS data showed that the first syllable for one-stress was read shorter than for two-stress words (only in PA), $F 1(1,13)=21.24, p<.001, d=1.51, \eta_{\mathrm{p}}{ }^{2}$ $=.63, F 2(1,17)=1.96, n s, d=0.54, \eta_{\mathrm{p}}{ }^{2}=.11$; the second syllable for one-stress was read longer than for two-stress words, $F 1(1,13)=258.83, p<.001, d=4.40, \eta_{\mathrm{p}}{ }^{2}=.96, F 2(1,17)=25.82, p<.001, d=1.76, \eta_{\mathrm{p}}{ }^{2}$ $=.61$; the third syllable for one-stress was read shorter than for two-stress words, $F 1(1,13)=95.33, p<.001, d$ $=3.60, \eta_{\mathrm{p}}{ }^{2}=.88, F 2(1,17)=20.98, p<.001, d=1.43, \eta_{\mathrm{p}}{ }^{2}=.56$; and the fourth syllables between the word conditions were not significantly different (only in IA), $F 1(1,13)=12.40, p .01, d=0.69, \eta_{\mathrm{p}}{ }^{2}=.49, F 2(1,17)=$ 2.33, $n s, d=0.37, \eta_{\mathrm{p}}{ }^{2}=.13$.

Post-hoc Bonferroni tests for the simple main effect of Position for one-stress words with for NS data showed that the first syllable was read shorter than the second and fourth but longer than the third syllables (only in PA), and the second and fourth were read longer than the third syllables, $F 1(3,39)=48.09, p<.001, \eta_{\mathrm{p}}{ }^{2}=.79, F 2(3$, $51)=4.85, p<.01, \eta_{\mathrm{p}}{ }^{2}=.23$, while it showed that, for two-stress words, the second syllable was shortest and the fourth longest, with no significant difference between the first and third syllables, $F 1(3,39)=73.86, p$ $<.001, \eta_{\mathrm{p}}{ }^{2}=.86, F 2(3,51)=12.32, p<.001, \eta_{\mathrm{p}}{ }^{2}=.43$. Figure 4 illustrates the Bonferroni $t$-tests for the mean syllable duration in sentence reading for precision. The fourth syllables for both readers in both word conditions were read longest among the syllables, but the results were not shown in the figure, in the interest of simplicity. 


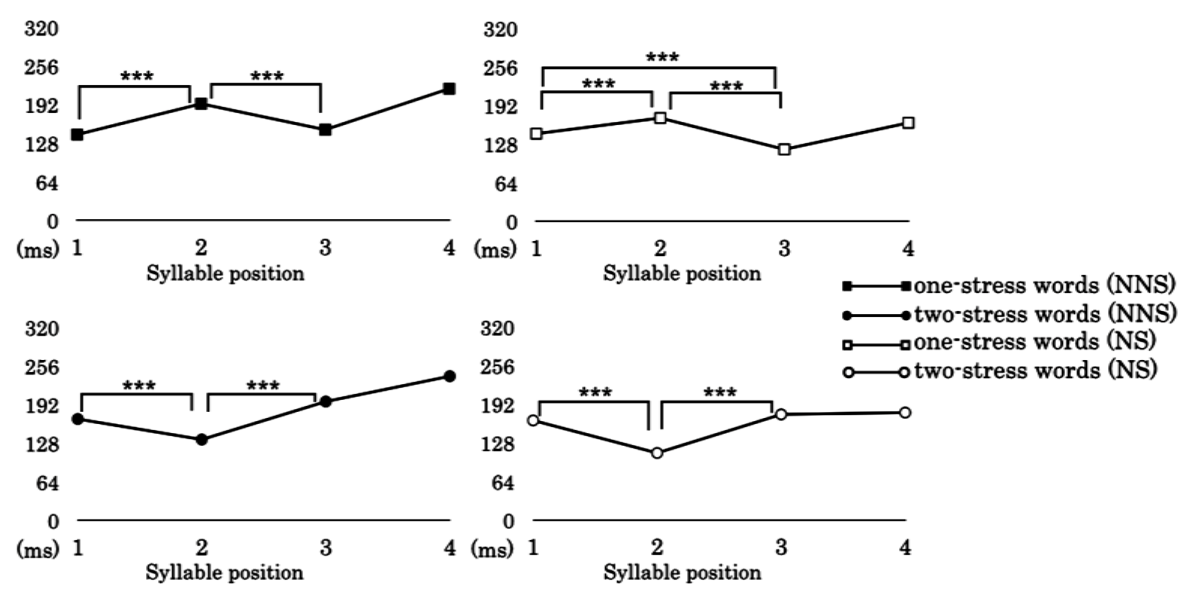

Figure 4. Results of the simple main effect of Position by Stress for the mean syllable duration in sentence reading for one-stress for NNS (the top left) and for NS (the top right) and two-stress words for NNS (the bottom left) and for NS (the bottom right). Note: ${ }^{* * * *} p<.001$.

\subsection{Mean Syllable Intensity (dB) in Sentence Reading}

In syllable intensity $(\mathrm{dB})$ measures for NNS data, there was a non-significant main effect for Stress, $F 1(1,13)=$ $0.05, n s, \eta_{\mathrm{p}}{ }^{2}=.01, F 2(1,17)=0.04, n s, \eta_{\mathrm{p}}{ }^{2}=.01$; a significant main effect for Position (only in PA), $F 1(3,39)$ $=5.04, p<.01, \eta_{\mathrm{p}}{ }^{2}=.28, F 2(3,51)=0.95, n s, \eta_{\mathrm{p}}{ }^{2}=.06$; and the Stress and Position interaction, $F 1(3,39)=$ $60.19, p<.001, \eta_{\mathrm{p}}{ }^{2}=.83, \mathrm{~F} 2(3,51)=16.51, p<.001, \eta_{\mathrm{p}}{ }^{2}=.50$, while NS data showed a non-significant main effect for Stress, $F 1(1,13)=2.17$, $n s, \eta_{\mathrm{p}}{ }^{2}=.15, F 2(1,17)=0.69, n s, \eta_{\mathrm{p}}{ }^{2}=.04$; a significant main effect for Position, $F 1(3,39)=30.55, p<.001, \eta_{\mathrm{p}}{ }^{2}=.71, F 2(2.38,40.41)=6.45, p<.01, \eta_{\mathrm{p}}{ }^{2}=.27$; and the Stress and Position interaction, $F 1(3,39)=146.22, p<.001, \eta_{\mathrm{p}}{ }^{2}=.92, F 2(2.22,37.79)=22.02, p<.001, \eta_{\mathrm{p}}{ }^{2}=.57$. Figure 5 summarizes the results of the simple main effect of Stress for both the mean syllable duration and intensity in sentence reading for NNS and NS.

The simple main effect of Stress for NNS data with post-hoc Bonferroni tests showed that the first syllable for one-stress had lower intensity than for two-stress words, $F 1(1,13)=22.13, p<.001, d=0.37, \eta_{\mathrm{p}}{ }^{2}=.63, F 2(1$, $17=4.94, p<.05, d=0.65, \eta_{\mathrm{p}}{ }^{2}=.23$; the second syllable for one-stress had higher intensity than for two-stress words, $F 1(1,13)=52.57, p<.001, d=0.73, \eta_{\mathrm{p}}{ }^{2}=.81, F 2(1,17)=24.74, p<.001, d=1.27, \eta_{\mathrm{p}}{ }^{2}=.60$; the third syllable for one-stress had lower intensity than for two-stress words, $F 1(1,13)=145.91, p<.001, d=0.57, \eta_{\mathrm{p}}{ }^{2}$ $=.92, F 2(1,17)=14.03, p<.01, d=1.02, \eta_{\mathrm{p}}{ }^{2}=.46$; and the fourth syllables were not significantly different between the conditions (only in IA), $F 1(1,13)=9.74, p<.01, d=0.20, \eta_{\mathrm{p}}{ }^{2}=.43, F 2(1,17)=2.98, n s, d=0.47$, $\eta_{\mathrm{p}}{ }^{2}=.15$. The simple main effect of Position for one-stress words with post-hoc Bonferroni tests for NNS data showed significant differences only between the second and the other syllables, with the second syllable having highest intensity, $F 1(3,39)=33.64, p<.001, \eta_{\mathrm{p}}{ }^{2}=.73, F 2(3,51)=7.68, p<.001, \eta_{\mathrm{p}}{ }^{2}=.32$, while two-stress words showed that the first and third syllables had higher intensities than the second (only in PA) and fourth, which had the lowest intensity, $F 1(3,39)=21.58, p<.001, \eta_{\mathrm{p}}{ }^{2}=.63, F 2(3,51)=4.96, p<.01, \eta_{\mathrm{p}}{ }^{2}=.23$.

Post-hoc Bonferroni tests for the simple main effect of Stress by Position for NS data revealed that the first syllable for one-stress had lower intensity than for two-stress words, $F 1(1,13)=114.14, p<.001, d=1.25, \eta_{\mathrm{p}}{ }^{2}$ $=.90, F 2(1,17)=22.29, p<.001, d=1.13, \eta_{\mathrm{p}}{ }^{2}=.57$; the second syllable for one-stress had higher intensity than for two-stress words, $F 1(1,13)=174.65, p<.001, d=1.21, \eta_{\mathrm{p}}{ }^{2}=.94, F 2(1,17)=24.92, p<.001, d=1.54$, $\eta_{\mathrm{p}}{ }^{2}=.60$; the third for one-stress had lower intensity than for two-stress words, $F 1(1,13)=58.22, p<.001, d=$ $0.94, \eta_{\mathrm{p}}{ }^{2}=.82, F 2(1,17)=14.54, p<.01, d=1.09, \eta_{\mathrm{p}}{ }^{2}=.47$; and the fourth syllable for one-stress had higher intensity than for two-stress words, $F 1(1,13)=26.60, p<.001, d=0.38, \eta_{\mathrm{p}}{ }^{2}=.68, F 2(1,17)=4.55, p<.05, d$ $=0.54, \eta_{p}{ }^{2}=.22$. Post-hoc Bonferroni tests for the simple main effects of Position for one-stress words for NS data showed that the second syllable had the highest intensity, and no significant differences among the other syllables, $F 1(3,39)=85.41, p<.001, \eta_{\mathrm{p}}{ }^{2}=.87, F 2(3,51)=17.18, p<.001, \eta_{\mathrm{p}}{ }^{2}=.51$, while it showed that, for two-stress words, the first and third syllables had higher intensity than the second and fourth syllables, $F 1(3,39)$ $=82.96, p<.001, \eta_{\mathrm{p}}{ }^{2}=.87, \mathrm{~F} 2(3,51)=13.12, p<.001, \eta_{\mathrm{p}}{ }^{2}=.44$. Figure 6 illustrates the Bonferroni $t$-tests for the mean syllable intensity in sentence reading for precision. 


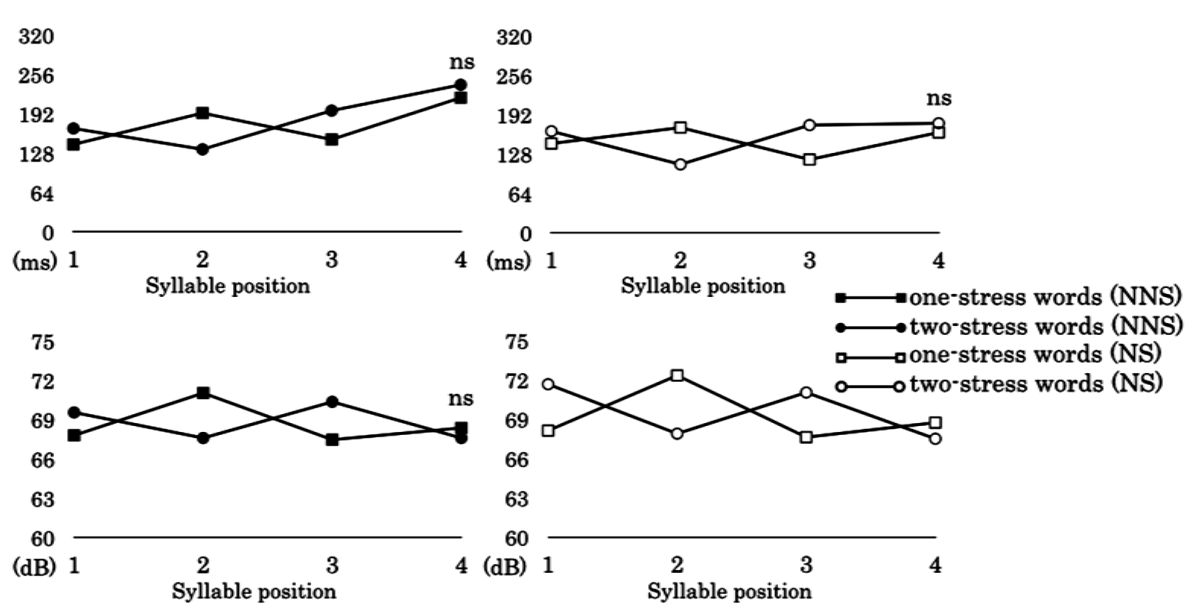

Figure 5. Results of the simple main effect of Stress for the mean syllable duration (top) for NNS (the top left) and NS (the top right) and for the mean syllable intensity (bottom) for NNS (the bottom left) and NS (the bottom right) in sentence reading. Note: All conditions without asterisks reached statistically significant levels.
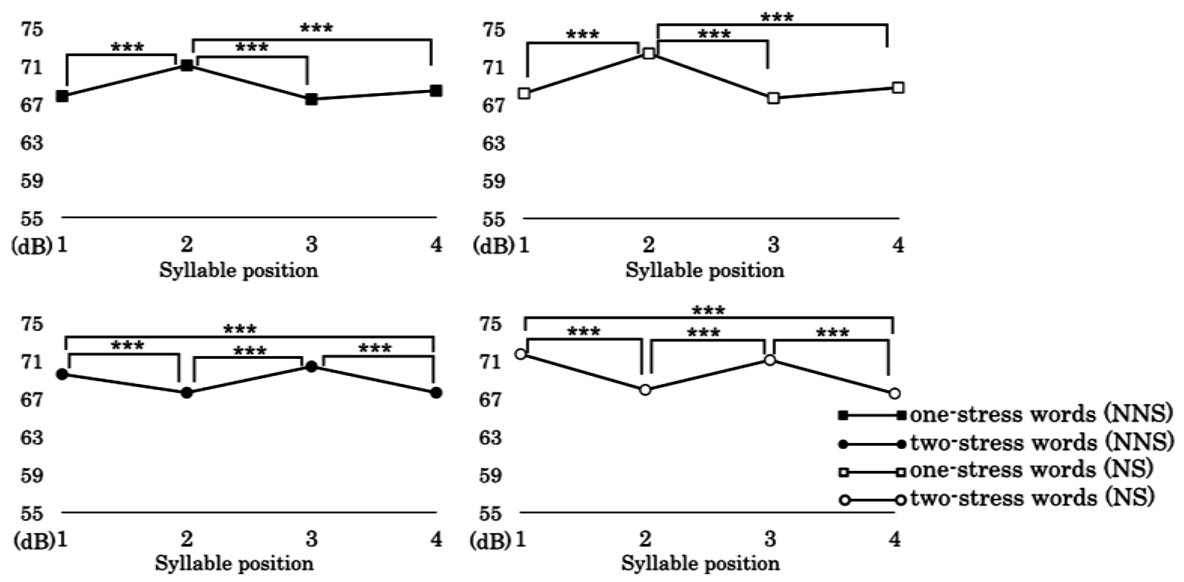

Figure 6. Results of the simple main effect of Position by Stress for the mean syllable intensity in sentence reading for one-stress for NNS (the top left) and for NS (the top right) and twostress words for NNS (the bottom left) and for NS (the bottom right). Note: ${ }^{* * *} p<.001$.

\subsection{Summary of the Results}

Before the discussion, we briefly summarize the results. Regarding the word duration measures, paired-sample $t$-tests indicate a longer duration on two-stress words than on one-stress words in both reading conditions for the NNS and NS data. Additionally, both one- and two-stress words were read longer in isolation than in the sentence reading condition. Next, a 2 (Stress: one-stress words, two-stress words) $\times 2$ (Position: first, second, third, fourth syllables) ANOVA and the following Bonferroni post-hoc multiple comparisons for each NNS and NS group on the mean syllable duration measure in isolation reading showed that both groups of readers recognized the difference between one- and two-stress words, but the mean durations of the first syllables were not significantly different (see Figure 2). This result is reflected in the non-significant difference in the mean intensity between the first and second syllables for two-stress words pronounced by NNS (see Figure 3), whereas NS clearly read the first (stressed) syllable longer than the second (unstressed) syllable.

On the other hand, in the sentence reading condition, both groups of readers not only accurately recognized the difference between one- and two-stress words, but read stressed syllables (the second syllable for one-stress words and the first and third syllables for two-stress words) longer than unstressed syllables at significant levels. The common characteristic among participants and reading conditions is that they tended to read the fourth syllable significantly longer than the other syllables and to place the least stress on it. 


\section{Discussion}

Our utmost interest for the present study was to see whether Japanese EFL learners place lexical stress appropriately in oral reading. Overall, our results showed similar oral reading patterns between Japanese and L1-English participants across the two reading conditions. Although we failed to provide consistent results between the PA and IA on some of the measures, the results clearly indicate that the readers in both groups tended to read two-stress words longer than one-stress words. Moreover, the post-hoc Bonferroni $t$-tests showed clear distinctions between the stressed and unstressed syllables both between one- and two-stress words and within each word condition on the mean syllable duration and intensity measures, especially in the sentence reading condition. The stressed syllables (the second syllable for one-stress words and the first and third syllables for twostress words) were read significantly longer with higher intensity than the unstressed ones. Accordingly, the present findings demonstrate that even intermediate EFL readers more or less recognize the differences of lexical stress for each word and reflect their recognition appropriately in oral performance, even though their L1 does not have the same prosodic features as their L2. In other words, the EFL learners in this study produce the correct prosody at the word level, and its production does not "disassociate" with their comprehension (Goth \& Nakayama, 2011). Meanwhile, the same pattern of results obtained for the isolation and sentence context readings indicates that sentence prosody did not affect the metrical characteristic of the lexical stress of the target words. This may imply that the Japanese participants have attained concrete and accurate knowledge about lexical stress for each word through EFL instruction. Although we cannot provide a definitive answer regarding how they acquired the separate and independent lexical stress information, it can be speculated that at least they process lexical access during the phase of lexical access, as L1 speakers do (Gutiérrez-Palma \& Palma-Reyes, 2008). Another point to be mentioned is the unique characteristic seen in both groups of readers, i.e., the longest mean syllable durations and lowest mean syllable intensities of the fourth syllables. We assume that this is an indication of the meaningless lasting reading of the last syllable (Kuriyagawa \& Sawashima, 1989).

Reading with prosody necessitates reading skills development and reading fluency. To date, only a handful of studies have focused on assessing oral reading performances acoustically among L2 learners. The present study thus attempts to contribute to this line of research by collecting further empirical data and to provide the initial step toward better understanding the relation between oral reading and the prosody of EFL learners. Although we confirmed the learners' accurate oral performances of stress assignment during oral reading even at the intermediate English level with limited L2 oral communication, the present data cannot provide sufficient information on why they performed so or whether the effects of L2 proficiency and/or L1 background or other related factors are interwoven. Acoustic research that integrates a theoretical framework is thus needed to develop this line of research to contribute to EFL instruction, as the research outcomes would help EFL teachers understand the aspects of prosodic features and to what degree they should spend time teaching this aspect.

\section{References}

Coltheart, M. (1981). The MRC Psycholinguistic Database. Quarterly Journal of Experimental Psychology, 33A, 497-505. http://dx.doi.org/10.1080/14640748108400805

Fodor, J. D. (1998). Learning to Parse? Journal of Psycholinguistic Research, 27, 285-319. http://dx.doi.org/10.1023/A:1023258301588

Fuchs, L. S., Fuchs, D., Hosp, M. K., \& Jenkins, J. R. (2001). Oral Reading Fluency as an Indicator of Reading Competence: A Theoretical, Empirical, and Historical Analysis. Scientific Studies of Reading, 5, 239-256. http://dx.doi.org/10.1207/S1532799XSSR0503_3

Goss, S., \& Nakayama, M. (2011). Prosody and Comprehension in Oral Reading by L2 Japanese Learners. Second Language, 10, 33-50.

Gutiérrez-Palma, N., \& Palma-Reyes, A. (2008). On the Use of Lexical Stress in Reading Spanish. Reading and Writing: Academic Disciplinary Journal, 21, 645-660. http://dx.doi.org/10.1007/s11145-007-9082-x

Hirata, Y. (2004). Effects of Speaking Rate on the Vowel Length Distinction in Japanese. Journal of Phonetics, 32, 565-589. http://dx.doi.org/10.1016/j.wocn.2004.02.004

Hirotani, M., Frazier, L., \& Rayner, K. (2006). Punctuation and Intonation Effects on Clause and Sentence Wrap-Up: Evidence from Eye Movements. Journal of Memory and Language, 54, 425-443. http://dx.doi.org/10.1016/j.jml.2005.12.001

Hoequist Jr., C. (1983). Syllable Duration in Stress-, Syllable-, and Mora-Timed Languages. Phonetica, 40, 203-237. http://dx.doi.org/10.1159/000261692 
JACET Committee of Basic Words Revision (Ed.) (2003). JACET List of 8000 Basic Words: JACET 8000. Tokyo: JACET. Jeon, E. H. (2013). Oral Reading Fluency in Second Language Reading. Reading in a Foreign Language, 24, 186-208.

Jiang, X., Sawaki, Y., \& Sabatini, J. (2012). Word Reading Efficiency, Text Reading Fluency, and Reading Comprehension among Chinese Learners of English. Reading Psychology, 33, 323-349. http://dx.doi.org/10.1080/02702711.2010.526051

Kuhn, M. R., Schwanenflugel, P. J., \& Meisinger, E. B. (2010). Aligning Theory and Assessment of Reading Fluency: Automaticity, Prosody, and Definitions of Fluency. Reading Research Quarterly, 45, 230-251. http://dx.doi.org/10.1598/RRQ.45.2.4

Kuriyagawa, F., \& Sawashima, M. (1989). Word Accent, Devoicing and Duration of Vowels in Japanese. Annual Bulletin of the Research Institute, 23, 85-108.

Merriam-Webster's Online Dictionary (11th ed.) (n.d.). Retrieved June 16, 2014. http://www.m-w.com/dictionary

Miller, J., \& Schwanenflugel, P. J. (2006). Prosody of Syntactically Complex Sentences in the Oral Reading of Young Children. Journal of Educational Psychology, 98, 839-853. http://dx.doi.org/10.1037/0022-0663.98.4.839

Miller, J., \& Schwanenflugel, P. J. (2008). A Longitudinal Study of the Development of Reading Prosody as a Dimension of Oral Reading Fluency in Early Elementary School Children. Reading Research Quarterly, 43, 336-354. http://dx.doi.org/10.1598/RRQ.43.4.2

Perfetti, C. A. (2003). The Universal Grammar of Reading. Scientific Studies of Reading, 7, 3-24. http://dx.doi.org/10.1207/S1532799XSSR0701_02

Perfetti, C., Cao, F., \& Booth, J. (2013). Specialization and Universals in the Development of Reading Skill: How Chinese Research Informs a Universal Science of Reading. Scientific Studies of Reading, 17, 5-21. http://dx.doi.org/10.1080/10888438.2012.689786

Schreiber, P. A. (1991). Understanding Prosody’s Role in Reading Acquisition. Theory into Practice, 30, $158-164$. http://dx.doi.org/10.1080/00405849109543496

Stephens, M. A. (2011). Why Exposure to Prosody Should Precede the Teaching of Reading. The Language Teacher, 35, 68-73.

Wagner, M., \& Watson, D. G. (2010). Experimental and Theoretical Advances in Prosody: A Review. Language and Cognitive Processes, 25, 905-945. http://dx.doi.org/10.1080/01690961003589492

Yamashita, J., \& Amano, S. (2011). Relationship of Oral Reading Prosody to English Language Proficiency in Japanese EFL Learners: A Preliminary Study. JACET Chubu Journal, 9, 155-168. 
Scientific Research Publishing (SCIRP) is one of the largest Open Access journal publishers. It is currently publishing more than 200 open access, online, peer-reviewed journals covering a wide range of academic disciplines. SCIRP serves the worldwide academic communities and contributes to the progress and application of science with its publication.

Other selected journals from SCIRP are listed as below. Submit your manuscript to us via either submit@scirp.org or Online Submission Portal.
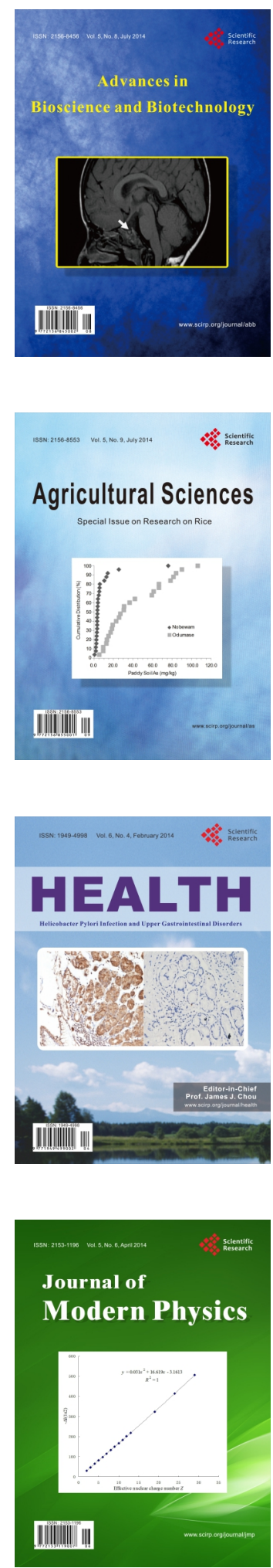
